\title{
Ionospheric electromagnetic perturbations observed on DEMETER satellite before Chile M7.9 earthquake*
}

\author{
Xuemin Zhang * Jiadong Qian Xinyan Ouyang \\ Xuhui Shen Jin'an Cai and Shufan Zhao \\ Institute of Earthquake Science, China Earthquake Administration, Beijing 100036, China
}

\begin{abstract}
Based on the ionospheric electromagnetic data observed on DEMETER satellite of France, the ionospheric electromagnetic signals were analyzed within 10 days before Chile $M 7.9$ earthquake on November 14, 2007. It is found that, low frequency electromagnetic disturbances began to increase in a large scale of latitude, and reached to a maximum one week prior to the earthquake, and at about three days before the quake, the peak values shifted to lower latitude. Taking three days as a group, spatial images of a few parameters were analyzed, from which it can be seen during the five days prior to this earthquake, the amplitude and scale of anomalies are enlarged, while the epicenter is located at the boundary of anomalous region. The anomalous tempo-spatial variation in electron density prior to the earthquake were also obtained in terms of tracing the data from revisited orbits in half a year prior to the quake.
\end{abstract}

Key words: DEMETER satellite; ionosphere; electromagnetic disturbance; electron density CLC number: P352.3

Document code: A

\section{Introduction}

Earthquake short-term prediction is one of most challenging issues in the world at present. Observation and research illustrate that lots of anomalous electromagnetic signals have been recorded a few days or hours prior to the earthquakes. Due to the limits of surface observation, the area and events included in the study were largely restricted. Since 1980s, electromagnetic observations on satellite have been developed in many countries, and spatial electromagnetic precursors have been reported since then (Larkina et al, 1983; Chmyrec et al, 1989; Parrot and Mogilevsky, 1989; Pulinets and Legen'ka, 2003; Molchanov et al, 1993), which provides a new observing technique for the researches of seismic-electromagnetic effects.

On 29 June 2004, DEMETER satellite, the first satellite for earthquake monitoring from space, was launched successfully. Researchers from many countries have been participating in the studies of DEMETER's data, which has become a new item to apply satellite

\footnotetext{
* Received 8 September 2008; accepted in revised form 13 March 2009; published 10 June 2009.

- Corresponding author. e-mail: zhangxm96@126.com
}

electromagnetic observation to earthquake science. This paper analyzes the DEMETER satellite data of continuous 10 days before the M7.9 earthquake in Chile on 14 November 2007. At the meantime, for the key orbit, the revisited characteristics of every 16 days are traced and compared to make sure the relationship between anomalous perturbations and the earthquake. The results show that a few parameters presented apparent disturbances in ionosphere before the earthquake. Finally the evolution feature of anomaly was analyzed in detail.

\section{DEMETER satellite}

DEMETER satellite is designed to study ionospheric disturbances related to earthquake, volcano and human activity, and to detect the electromagnetic environment in global scale (Berthelier et al, 2006a, b; Lebreton et al, 2006; Parrot et al, 2006a; Sauvaud et al, 2006). The satellite has quasisolar-synchronous circular orbit with declination $98.23^{\circ}$, weight $130 \mathrm{~kg}$ and height $710 \mathrm{~km}$ (which decreased to $660 \mathrm{~km}$ in the middle of December, 2005). Its life was supposed to be two years. However, it is still operating now.

A set of instruments were deployed on the satellite, including ICE to detect electric field from DC to 3.5 
$\mathrm{MHz}$; IMSC to measure the magnetic field from a few $\mathrm{Hz}$ to $20 \mathrm{kHz}$; IAP to detect ion density and temperature and so on; ISL, Langmuir probe to measure the electron density and temperature. Two kinds of data with different operating modes are provided: survey mode with low sampling rate and burst mode with high sampling rate as the satellite flies over the seismic zones. The mission center of DEMETER provides the data that can guide can be referred to the website of DEMETER, http://demeter.cnrs-orleans.fr.

\section{Data analysis}

A strong earthquake of M7.9 occurred in Chile $\left(22.1^{\circ} \mathrm{S}, 69.7^{\circ} \mathrm{N}\right)$, at $23: 40$ on November 14,2007 , with a focal depth of $40 \mathrm{~km}$, according to the report from China

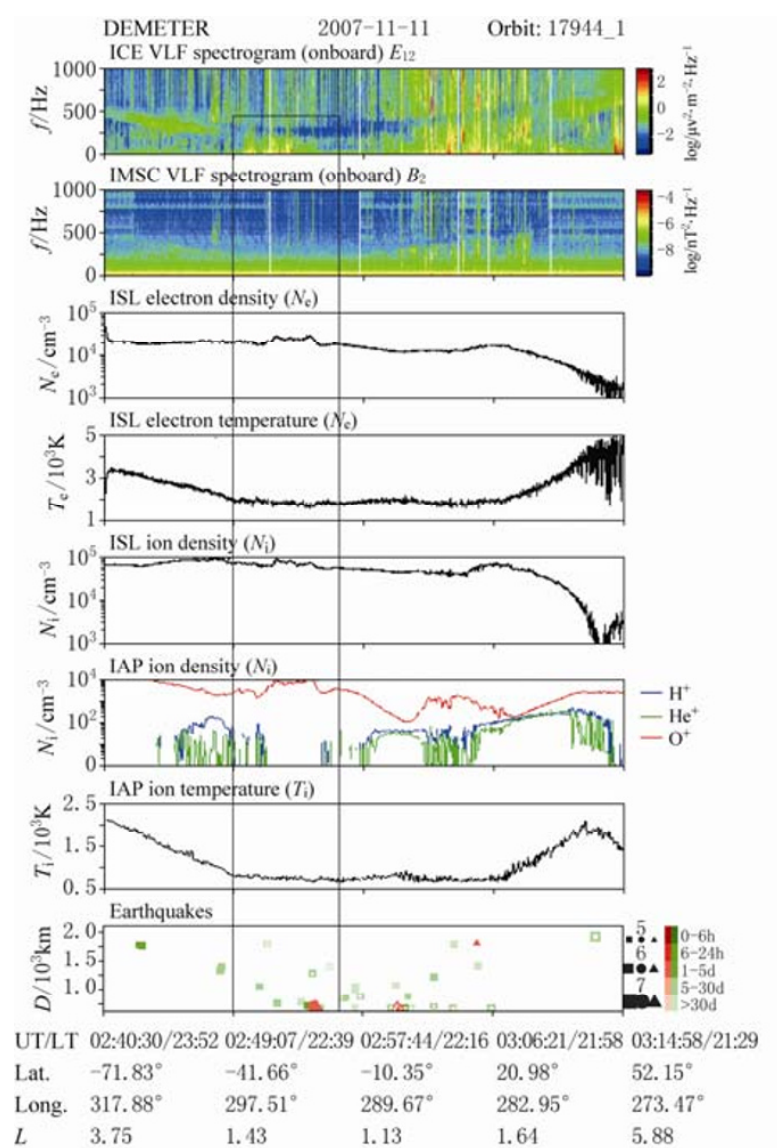
be downloaded and Quicklook images. Detailed data

Earthquake Networks Center. Figure 1 shows some images from DEMETER data set. In Figure 1, two black rectangles are plotted on each images, denoting the satellite locations in a distance of $2000 \mathrm{~km}$ away from the epicenter, where some parameters showed peculiar behaviors. Electromagnetic perturbations were observed above the epicentral area a few days prior to the earthquake. It can be seen that low-frequency disturbances and step increase of density $\left(N_{\mathrm{e}}\right)$ and ion density $\left(N_{\mathrm{i}}\right)$ appeared when the satellite was within a distance of about $750 \mathrm{~km}$ to the epicenter on the image of November 11. On November 13, one day before the earthquake, almost every parameter and its corresponding magnetic conjugate point appeared intensive disturbances on a half-orbit above the epicentral area. Among those disturbances, the ion temperature $T_{\mathrm{i}}$ is the strongest.

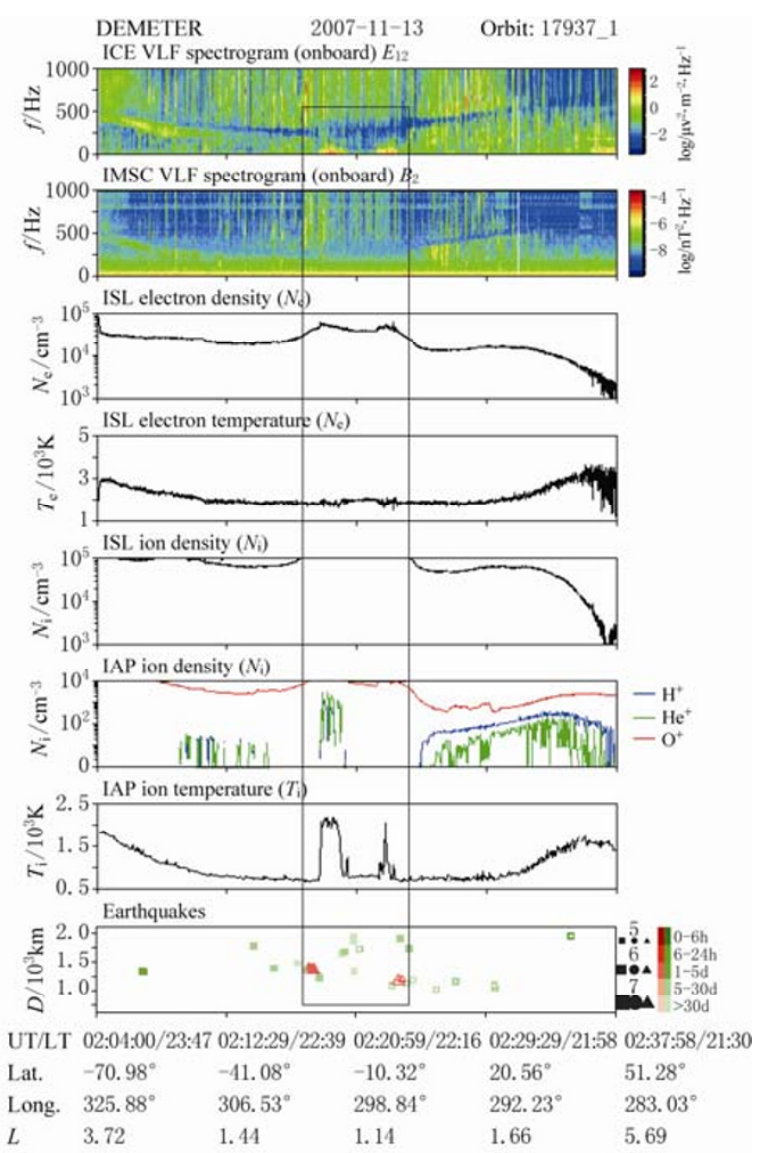

Figure 1 The anomalous phenomena of many parameters observed on DEMETER satellite before Chile M7.9 earthquake.

\subsection{Geomagnetic conditions}

In order to reveal the temporally evolutional process of anomalous signals before the earthquake, 10 days data before the event were collected and shown in Figure 1. Thirteen orbits passing the epicentral area during this time interval were included. Based on the statistics (Pulinets and Legen'ka, 2003), we found the seismic ionospheric anomalies generally occurred in a week before strong earthquake. The projections of those orbits on surface are shown in Figure 2. The results of com- 
parison will be described as follows.

\subsection{Anomalies in geomagnetic field}

In order to identify the earthquake-related anomalies observed on the satellite, it is necessary to exclude the effects from solar activity, planetary magnetic field and so on. Figure 3 shows the $K_{\mathrm{p}}$ index and Dst index, which are related to the solar activity and geomagnetic condition. It can be seen that, all $K_{\mathrm{p}}$ data are below 3 and Dst higher than $-20 \mathrm{nT}$, showing the time interval before earthquake mentioned above was relatively quiet one.

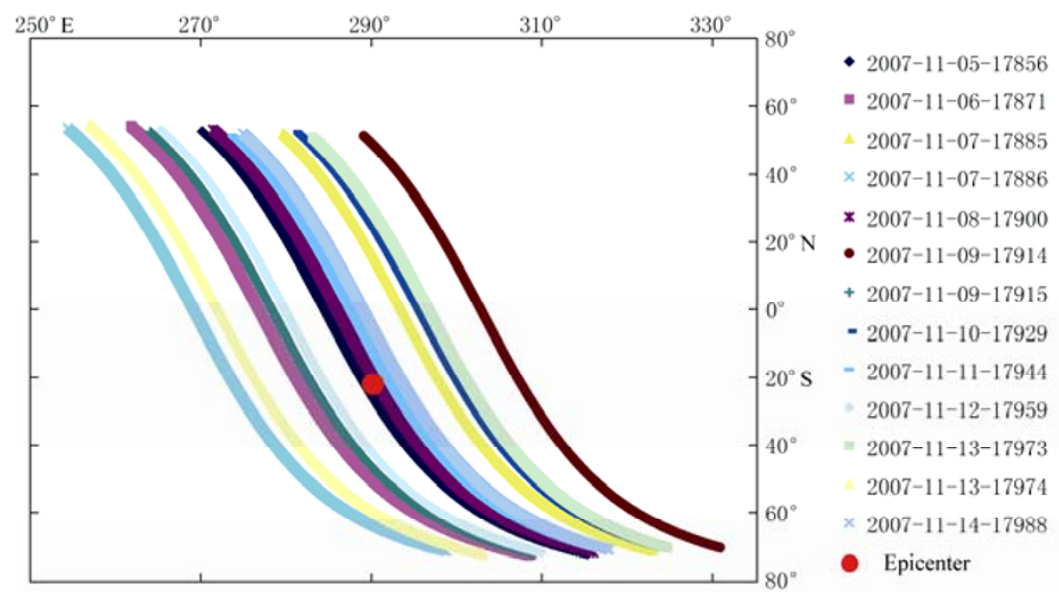

Figure 2 The projected orbits at a scale of $2000 \mathrm{~km}$ around the epicenter during 5-14 November 2007.
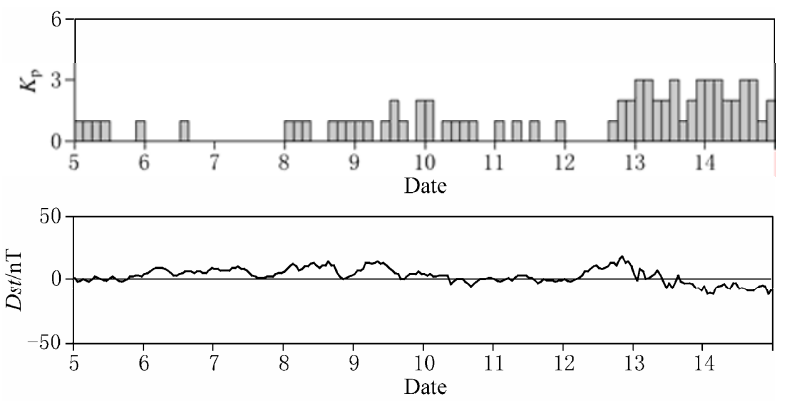

Figure 3 Magnetic activity condition during 5-14 November 2007.

\subsection{Anomalies in electric field at some frequency range}

Figure 4 shows the results of the analysis for the electric field spectrums smoothing averaged by five points with center at about $40 \mathrm{~Hz}$, three days as a group and four days for the third group, all orbits within $45^{\circ} \mathrm{S}-15^{\circ} \mathrm{N}$. It can be seen that for the first group, the curves of three orbits from 5 to 7 November are basically consistent with each other, showing smoothly spatial variation in each orbit with logarithm values of $A$ (electric field spectrum density), ranging from -2 to 0 ; while for the second group, four orbits from 8 to 10 November are still similar to each other, but have larger differences with each other, especially within $35^{\circ} \mathrm{S}-20^{\circ} \mathrm{S}$, spectrum disturbance increases obviously. Relative to epicenter, the disturbances distribute in higher-latitude areas. Moreover, for the last group, four orbits from 11 to 14 November have large differences with each other and show drastically spatial variation, especially on the orbit on 13 November with logarithm values ranging from -1 to 1 at $15^{\circ} \mathrm{S}-5^{\circ} \mathrm{S}$. As a comparison to the anomalies, the $110 \mathrm{~Hz}$ electric field spectrums from the same orbit on 13 November are selected and analyzed with the same approach. The results show they present similar behaviors, but with smaller amplitude at $100 \mathrm{~Hz}$, showing it is a set of low-frequency signals.

\subsection{Analysis of anomalies in electron density $N_{\mathrm{e}}$ in terms of revisited orbits}

The variation of ion temperature and density in ionosphere is affected by space electromagnetic environment. In order to verify whether or not the anomalous signals on the orbit on 13 November mentioned above could be related to the earthquake of $M 7.9$, the temporal evolution processes of $N_{\mathrm{e}}$ in all revisited orbits during the time period from May to November, 2007, have been analyzed as shown in Figure 5. The revisited period of DEMETER satellite is 16 days, which shows similar location for all the revisited orbits just as shown in the last image in Figure 5, so that one could find the temporal changes at the same position for any parameter through comparing the data recorded by all the included revisited orbits. 12 orbits collected with the observing time error at same point did not exceed $30 \mathrm{~s}$, with the largest longitudinal difference among them not exceed- 
ing $0.5^{\circ}$. Therefore the data in different orbit is well comparable, just like a kind of mobile and repeated observation on ground. The results in Figure 5 show that, the spatial variation of $N_{\mathrm{e}}$ on the four orbits during May to July of 2007 were almost the same with a single peak at equator and the highest density value is only $3 \times 10^{4}$ $\mathrm{cm}^{-3}$. During the period from August to October of 2007, six revisited orbits were included with much larger differences among them: two orbits present a little spatial variation; three orbits show peak values of $4.5 \times 10^{4} \mathrm{~cm}^{-3}$ within $20^{\circ} \mathrm{S}-5^{\circ} \mathrm{N}$ and other latitudinal area varied steadily; and one orbit on October 28 that is 17 days before the Chile earthquake, largely different from the other orbits and its peak value being about $7 \times 10^{4} \mathrm{~cm}^{-3}$ as well as with many high frequency disturbances accompanied in the orbit. It is noted that the orbit is the last revisited orbit to the one on November 13.
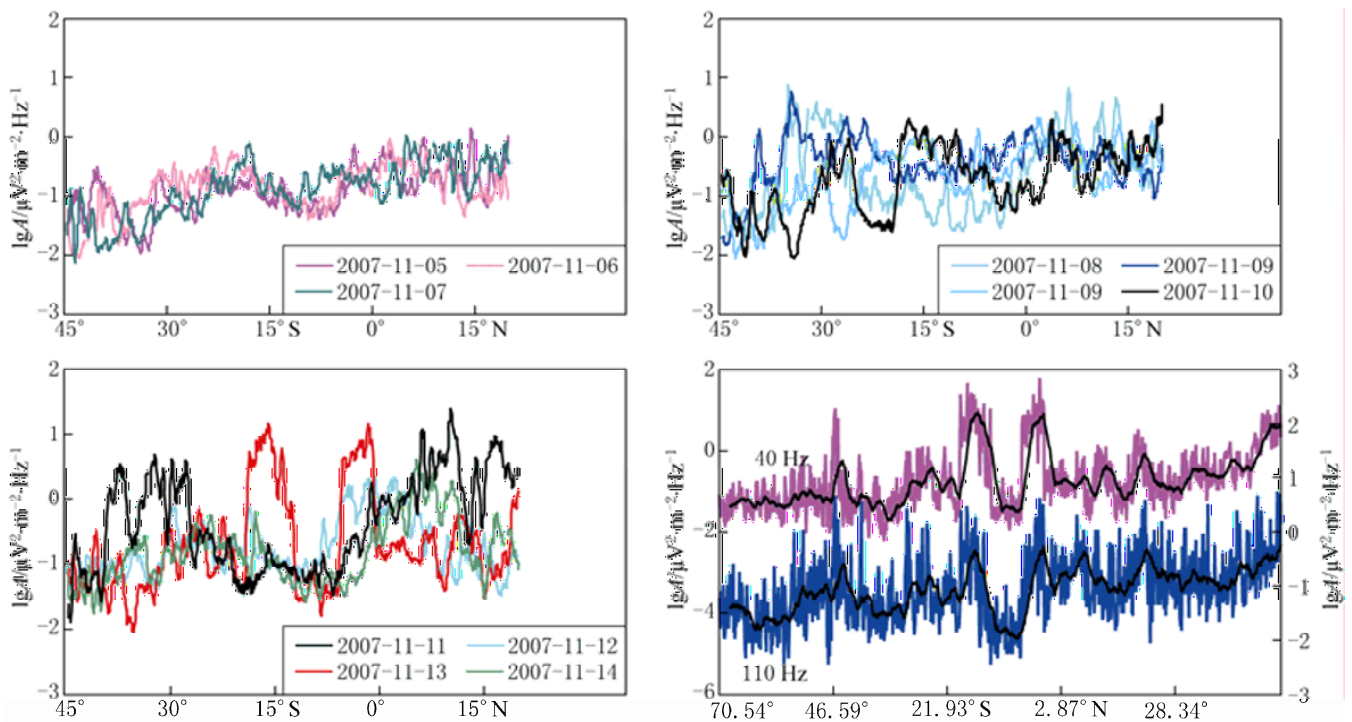

Figure 4 Evolution of $40 \mathrm{~Hz}$ electric field spectrums and comparison with that of $110 \mathrm{~Hz}$.
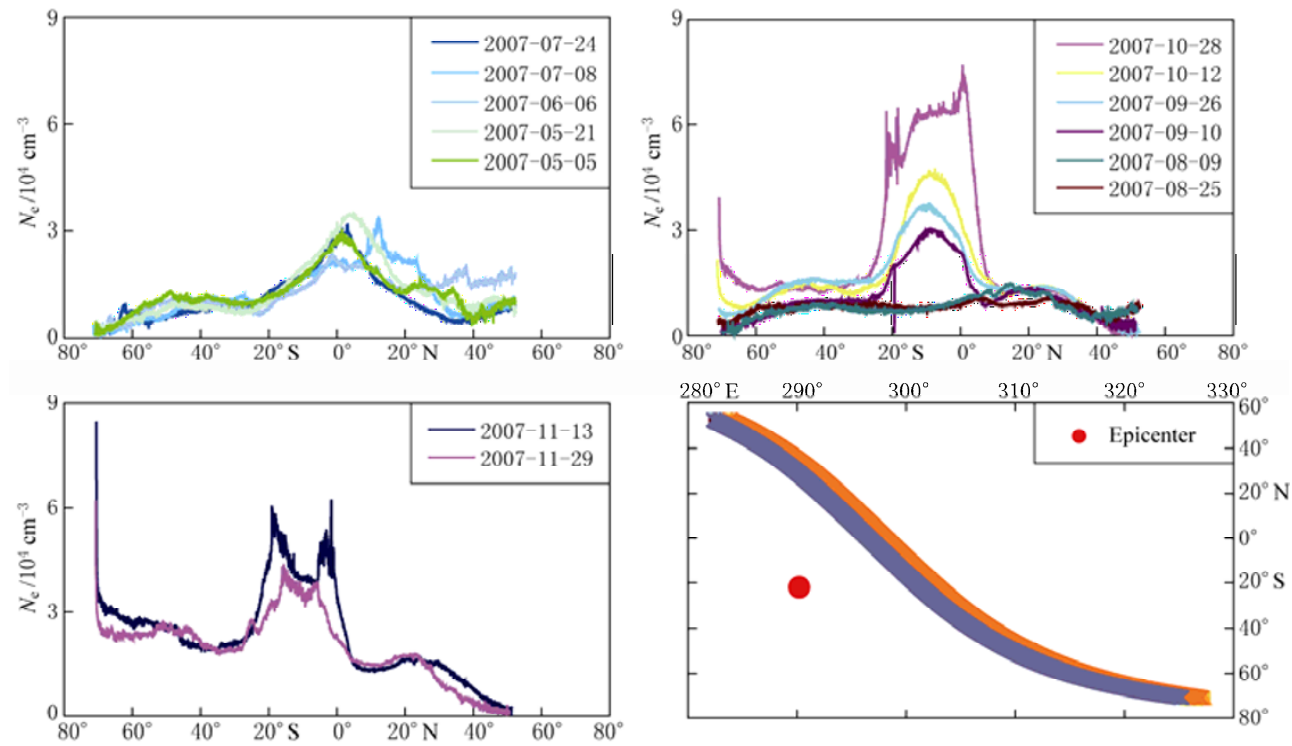

Figure $5 N_{\mathrm{e}}$ curves and their projection of all revisited orbits in half a year of 17973-1 orbit (2007-11-13).

The spatial variation of $N_{\mathrm{e}}$ on November 13 was a saddle-like shape with two peaks located within the range of $20^{\circ} \mathrm{S}-0^{\circ}$, the largest value of $6 \times 10^{4} \mathrm{~cm}^{-3}$, and some high frequency signals existing in the peak segment. For comparison, one revisited orbit on November 29 after the earthquake were also presented with its peak 
values reducing to $4 \times 10^{4} \mathrm{~cm}^{-3}$.

Combined all the curves, it could be concluded that the anomaly related to the Chile earthquake might start on October 28, and the spatial variation of $N_{\mathrm{e}}$ on November 13 curve presented a saddle-like shape with the center of the magnetic equator, which responds to the anomaly of VLF electric field. After the earthquake, the single peak in $N_{\mathrm{e}}$ curve decreased.

\section{Discussion and conclusions}

Based on analysis on the data observed on DEMETER satellite, the ionospheric electromagnetic anomalies before Chile M7.9 earthquake on 14 November 2007 can be summed up as follows.

1) The anomalous amplitude in electric field spectrums of 10 days data before the earthquake, especially in the low frequency range $(40 \mathrm{~Hz}$ and $110 \mathrm{~Hz})$ increased since November 8 and concentrated on the epicentral area since November 11, three days before the event, finally reached the largest one on November 13 . The anomalies disappeared after the earthquake.

2) According to the comparison among observations on revisited orbits during half a year, the anomaly of electron density $\left(N_{\mathrm{e}}\right)$ increases and shows saddle-like distribution with peak value of $6 \times 10^{4} \mathrm{~cm}^{-3}$ since 17 days prior to this earthquake and much smaller peak value on the first revisited orbit on November 29 after the earthquake.

As for the mechanism for the anomalous ionospheric disturbances, one might relate them to the possible micro-cracks development, the gravity acoustic wave and then the disturbed ionosphere (Molchanov et al, 2002). It is, however, not a simple model that can totally explain the coupling between the earthquake preparation and ionospheric anomalies, and further studies should be made on them.

Acknowledgements This paper is supported by Chinese National Science and Technology Program (2008BAC35B01) and Basic Research Project from Institute of Earthquake Science, China Earthquake
Administration. The authors are appreciated for the DEMETER Mission Center of France to provide the satellite observing data.

\section{References}

Berthelier J J, Godefroy M, Leblanc F, Malingre M, Menvielle M, Lagoutte D, Brochot J Y, Colin F, Elie F, Legendre C, Zamora P, Benoist D, Chapuis Y, Artru J and Pfaff R (2006a). ICE, the electric field experiment on DEMETER. Planet Space Sci 54: 456-471.

Berthelier J J, Godefroy M, Leblanc F, Seran E, Peschard D, Gilbert P and Artru J (2006b). IAP, the thermal plasma analyzer on DEMETER. Planet Space Sci 54: 487-501.

Chmyrec V M, Isaev N V, Bilichenko S V and Stanev G (1989). Observation by space-borne detectors of electric fields and hydromagnetic waves in the ionosphere over an earthquake center. Phys Earth Planet Interi 57: $110-114$.

Larkina V I, Nalivayko A V, Gershenzon N I, Gokhberg M B, Liperovskii V A and Shalimov S L (1983). Intercosmos-19 observation of VLF emissions associated with seismic activity. Geomagn Aeron 23: 842-846 (in Russian).

Lebreton J P, Stverak S, Travnicek P, Travnicek P, Maksimovic M, Klinge D, Merikallio S, Lagoutte D, Poirier B, Blelly P L, Kozacck Z and Salaquarda M (2006). The ISL Langmuir probe experiment and its data procession onboard DEMETER: Scientific objectives, description and first results. Planet Space Sci 54: 472-486.

Molchanov O A, Hayakawa V V, Afonin O A, Akentieva O A, Mareev E A and Trakhtengerts V Yu (2002). Possible influence of seismicity by gravity waves on ionospheric equatorial anomaly from data of IK-24 satellite 2. Equatorial anomaly and small-scale ionospheric turbulence. In: Hayakawa $\mathrm{M}$ and Molchanov O A eds. Seismo Electromagnetics (Lithosphere-Atmosphere-Ionosphere Coupling). Terrapub, Tokyo, 287-296.

Molchanov O A, Mazhaeva O A, Golyavin A N and Hayakawa M (1993). Observation by the Intercosmos-24 satellite of ELF-VLF electromagnetic emissions associated with earthquake. Ann Geophys 11: 431-440.

Parrot M, Benoist D, Berthelier J J, Chapuis Y, Colina F, Elie F, Fergeau P, Lagoutte D, Lefeuvre F, Legendre C, Leveque M, Pincon J L, Poirier B and Zamora H P (2006a). The magnetic field experiment IMSC and its data processing onboard DEMETER: Scientific objectives, description and first results. Planet Space Sci 54: 441-455.

Parrot M, Berthelier J J, Lebreton J P, Sauvaud J A, Santolik O and Blecki J (2006b). Examples of unusual ionospheric observations made by the DEMETER satellite over seismic regions. Phys Chem Earth 31: 486-495.

Parrot M and Mogilevsky M M (1989). VLF emissions associated with earthquakes and observed in the ionosphere and the magnetosphere. Phys Earth Planet Interi 57: 86-99.

Pulinets S A and Legen'ka A D (2003). Spatial-temporal characteristics of the large scale disturbances of the electron concentration observed in the F-region of the ionosphere before strong earthquake. Cosm Res 41: 221-229.

Sauvaud J A, Moreau T, Maggiolo R, Treilhou J P, Jacquey C, Cros A, Coutelier J, Rouzaud J, Penou E and Gangloff M (2006). High energy electron detection onboard DEMETER: The IDP spectrometer, description and first results on the inner belt. Planet Space Sci 54: 502-511. 